\title{
Estrogen metabolism in the human lung: impact of tumorigenesis, smoke, sex and race/ethnicity
}

\author{
Jing Peng ${ }^{1}$, Sibele I. Meireles ${ }^{1}$, Xia X $\mathbf{u}^{2}$, William E. Smith ${ }^{3}$, Michael J. Slifker ${ }^{1}$, Stacy \\ L. Riel ${ }^{1}$, Shumenghui Zhai ${ }^{4}$, Guo Zhang ${ }^{4}$, Xiang Ma ${ }^{4}$, Mindy S. Kurzer ${ }^{3}$, Grace X. Ma ${ }^{4}$ \\ and Margie L. Clapper ${ }^{1}$ \\ ${ }^{1}$ Cancer Prevention and Control Program, Fox Chase Cancer Center, Philadelphia, PA 19111, USA \\ ${ }^{2}$ Leidos Biomedical Research, Inc., Frederick, MD 21701, USA \\ ${ }^{3}$ Department of Food Science and Nutrition and Department of Medicine, University of Minnesota, St. Paul, MN 55108, USA \\ ${ }^{4}$ Center for Asian Health, Temple University, Philadelphia, PA 19140, USA
}

Correspondence to: Margie L. Clapper, email: Margie.Clapper@fccc.edu

Keywords: estrogen metabolism; 4-hydroxy estrogen; non-small cell lung cancer; tobacco smoke; never-smoking Chinese women

Received: August 18, $2017 \quad$ Accepted: September 30, $2017 \quad$ Published: November 01, 2017

Copyright: Peng et al. This is an open-access article distributed under the terms of the Creative Commons Attribution License 3.0 (CC BY 3.0), which permits unrestricted use, distribution, and reproduction in any medium, provided the original author and source are credited.

\section{ABSTRACT}

Previous data from this group demonstrate that the murine lung metabolizes estrogen. Production of the putative carcinogen 4-hydroxyestrogen (4-OHE) is elevated within the lungs of female vs. male mice and accelerated by tobacco smoke. The goal of this study was to determine if the human lung metabolizes estrogen and evaluate the impact of tumor formation, smoke, sex and race/ethnicity on metabolism. Urine and lung tissue (normal, tumor) were obtained from 49 non-small cell lung cancer patients. Healthy postmenopausal Caucasian $(n=19)$ and Chinese $(n=20)$ American women (never-smokers) donated urine. Quantitative RT-PCR analyses indicate that multiple estrogen synthesis and metabolism genes are expressed in human bronchoalveolar cells. Estrogen and its metabolites were measured in lung tissue and urine using liquid chromatography/tandem mass spectrometry. Wilcoxon rank tests were used for statistical comparisons. $\mathrm{E}_{1}, \mathrm{E}_{2}, \mathrm{E}_{3}$ and estrogen metabolites 2-OHE ${ }_{1}, 2-\mathrm{OHE}_{2}, 4-\mathrm{OHE}_{1}$ 4-OHE ${ }_{2}, 2-\mathrm{OME}_{1}$ and $2-\mathrm{OME}_{2}$ were detected at higher levels in tumor vs. adjacent normal tissue and in women vs. men $(P<0.05)$. The proportion of 4-OHEs was higher in tumors than in normal lung tissue $(P<0.05)$, and elevated in normal tissue from currentvs. never-smoking women $(P=0.006)$; similar trends were observed in urine. The proportion of 4-OHEs in the urine of postmenopausal Chinese American women was 1.8fold higher than that of Caucasian women $(P=0.015)$. These data indicate that estrogen metabolites are present in the human lung. A shift towards 4-hydroxylation during lung tumorigenesis may contribute to the risk conferred by smoking, sex or race/ethnicity.

\section{INTRODUCTION}

Smoking tobacco continues to be the primary risk factor for lung cancer development. However, the etiology of lung tumors that arise in never-smokers is much less clear ( $15 \%$ in men; $>50 \%$ in women worldwide) [1]. The percentage of never-smokers among women with lung cancer is much higher in Asia (60-80\%) than in the US (15\%) or Europe (20\%) [2]. Even Chinese American women residing on the West coast of the US face a risk of lung cancer that is 4-fold higher than that of non-Hispanic
American whites, after controlling for smoking status [3]. The basis for these sex and racial/ethnic differences in lung cancer incidence remains unknown.

Recent studies suggest that estrogen and progesterone play an important role in lung carcinogenesis [4]. While most studies have focused on receptor-mediated signaling, less attention has been given to the conversion of estrogen to oncogenic metabolites within the lung. In extrahepatic tissues, estrogens are hydroxylated by cytochrome P450 (CYP) 1A1 and 1B1 to form 2- and 4-hydroxylated estrogens (2-OHEs and 4-OHEs), respectively $[5,6]$. 
4-OHEs can bind and activate estrogen receptors (ERs) [6-8] and generate free radicals that cause DNA damage and oncogenic mutations [9]. 2-OHEs have weak estrogenic activity and are less reactive with DNA than 4-OHEs [7, 10, 11]. These catechol estrogens are conjugated via glucuronidation, sulfation and/or O-methylation for excretion [12]. Importantly, 2-methoxy estrogens (2OMEs), generated by catechol-O-methyltransferase (COMT), are potent inhibitors of tumor cell proliferation and angiogenesis, and are thus protective [13, 14]. High levels of 4-OHEs [15] and less 2-hydroxylation of parent estrogens confer a higher risk of breast cancer [16]. Our data indicate that CYP1B1, the enzyme responsible for the production of 4-OHEs, contributes to the progression of head and neck cancers [17]. In addition, we found that estrogen was extensively metabolized in the mouse lung to form 2-OHEs, 4-OHEs and 2-OMEs [18]. Furthermore, the level of 4-OHE is higher in the lungs of female mice and elevated following tobacco smoke exposure [18], resulting from induction of Cyp1b1 [19]. While several studies have shown that estrogen metabolism varies with smoking status [20] and race/ethnicity [21-25], the impact of these factors on estrogen metabolism in the human lung has not been investigated.

The goal of this study was to assess the ability of the human lung to metabolize estrogen and determine if metabolism is altered either during lung tumorigenesis or by tobacco smoke, sex or race/ethnicity. Elevated 4-hydroxylation of estrogen in lung tumors, smokers and Chinese American women suggests that 4-OHEs may be associated with lung cancer and sex/racial disparities. The results support further investigation of 4-OHEs as biomarkers of lung cancer risk, as well as targets for preventive intervention and treatment of lung cancer.

\section{RESULTS}

\section{Expression of estrogen synthesis and metabolism genes in human bronchoalveolar cells}

The ability of the human lung to synthesize and metabolize estrogen was assessed by examining the level of expression of relevant genes in bronchoalveolar cells isolated from normal and tumor tissue (16 patients; age 53 - 81): 11 women, 5 men; 12 ever-smokers and 4 neversmokers. Of the tissues evaluated (14 normal and 9 tumor), 6 were matched pairs. Transcripts of all 14 metabolic genes evaluated (CYP17A1, CYP19, HSD17B1, HSD17B3, HSD17B7, CYP21, HSD3B1, CYP1A1, CYP1B1, GSTA4, GSTM1, GSTT1, NQO1 and COMT), as well as ER $\alpha$ and $\beta$, were detectable within the human lung (Figure 1). Interestingly, expression of several estrogen synthesis

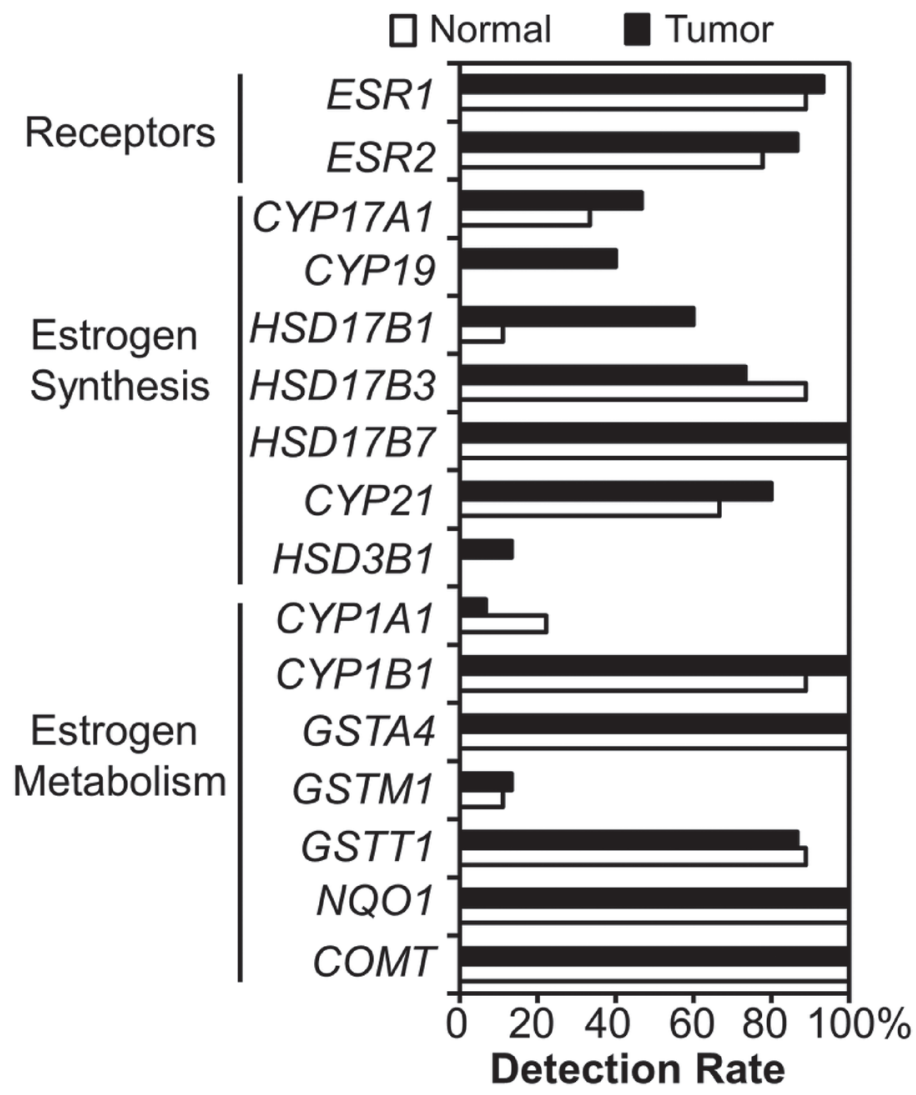

Figure 1: Expression of estrogen-related genes in human bronchoalveolar cells. Cells were microdissected from the tumor and adjacent normal lung of NSCLC patients. RNA was extracted and analyzed by quantitative real-time RT-PCR. The percentage of samples with detectable transcripts $(\mathrm{Ct}$ values $\leq 35)$ is plotted for each gene. 
Table 1: Levels of estrogen and its metabolites in lung tissue ${ }^{*}$

\begin{tabular}{|c|c|c|c|c|c|c|c|c|c|c|c|c|}
\hline \multirow[b]{2}{*}{ NORMAL } & \multicolumn{4}{|c|}{ All (pg/g tissue) } & \multicolumn{4}{|c|}{ Never Smokers (pg/g tissue) } & \multicolumn{4}{|c|}{ Current Smokers (pg/g tissue) } \\
\hline & $\begin{array}{c}\text { W } \\
n=18\end{array}$ & $\begin{array}{c}\text { M } \\
n=17\end{array}$ & $\begin{array}{c}P \\
\text { W vs. M }\end{array}$ & FDR & $\begin{array}{c}\mathrm{W} \\
n=9\end{array}$ & $\begin{array}{c}\text { M } \\
n=7\end{array}$ & $\begin{array}{c}P \\
\text { W vs. M }\end{array}$ & FDR & $\begin{array}{c}\mathrm{W} \\
n=9\end{array}$ & $\begin{array}{c}\text { M } \\
n=10\end{array}$ & $\begin{array}{c}P \\
\text { W vs. } M\end{array}$ & FDR \\
\hline $\mathrm{E}_{1}$ & 8.48 & 6.10 & $\underline{0.010}$ & 0.013 & 6.85 & 5.47 & 0.091 & 0.131 & 10.32 & 6.46 & $\underline{0.035}$ & 0.038 \\
\hline $\mathrm{E}_{2}$ & 15.12 & 8.98 & $\underline{4.3 \times 10^{-8}}$ & $1.9 \times 10^{-7}$ & 13.11 & 8.73 & $\underline{1.8 \times 10^{-4}}$ & 0.001 & 18.19 & 9.42 & $\underline{8.6 \times 10^{-5}}$ & $1.9 \times 10^{-4}$ \\
\hline $\mathrm{E}_{3}$ & 3.53 & 2.57 & $\underline{0.003}$ & 0.004 & 3.02 & 2.14 & 0.210 & 0.249 & 4.93 & 2.67 & $\underline{0.003}$ & 0.004 \\
\hline $2 \mathrm{OHE}_{1}$ & 2.69 & 1.86 & $\underline{3.2 \times 10^{-6}}$ & $6.9 \times 10^{-6}$ & 2.32 & 1.69 & $\underline{0.003}$ & 0.007 & 2.97 & 1.98 & $\underline{8.7 \times 10^{-5}}$ & $1.9 \times 10^{-4}$ \\
\hline $2 \mathrm{OHE}_{2}$ & 1.28 & 0.71 & $\underline{8.6 \times 10^{-8}}$ & $2.8 \times 10^{-7}$ & 1.04 & 0.72 & $\underline{0.002}$ & 0.007 & 2.16 & 0.68 & $\underline{4.3 \times 10^{-5}}$ & $1.4 \times 10^{-4}$ \\
\hline $4 \mathrm{OHE}_{1}$ & 0.39 & 0.21 & $\underline{1.8 \times 10^{-5}}$ & $3.3 \times 10^{-5}$ & 0.30 & 0.20 & $\underline{0.031}$ & 0.058 & 0.45 & 0.21 & $\underline{2.2 \times 10^{-5}}$ & $1.4 \times 10^{-4}$ \\
\hline $4 \mathrm{OHE}_{2}$ & 0.16 & 0.10 & $\underline{0.003}$ & 0.004 & 0.12 & 0.10 & 0.457 & 0.457 & 0.35 & 0.10 & $\underline{4.3 \times 10^{-5}}$ & $1.4 \times 10^{-4}$ \\
\hline $2 \mathrm{OME}_{1}$ & 1.47 & 0.51 & $\underline{3.1 \times 10^{-9}}$ & $4.0 \times 10^{-8}$ & 1.38 & 0.51 & $\underline{3.5 \times 10^{-4}}$ & 0.002 & 1.55 & 0.52 & $\underline{4.3 \times 10^{-5}}$ & $1.4 \times 10^{-4}$ \\
\hline $2 \mathrm{OME}_{2}$ & 0.88 & 0.26 & $\underline{8.4 \times 10^{-9}}$ & $5.4 \times 10^{-8}$ & 0.85 & 0.25 & $\underline{1.8 \times 10^{-4}}$ & 0.001 & 0.92 & 0.30 & $1.5 \times 10^{-4}$ & $2.8 \times 10^{-4}$ \\
\hline 2OHEs/Total & 0.11 & 0.12 & 0.883 & 0.883 & 0.10 & 0.12 & 0.351 & 0.380 & 0.12 & 0.12 & 0.356 & 0.356 \\
\hline 4OHEs/Total & 0.02 & 0.01 & 0.732 & 0.793 & 0.01 & 0.01 & $\underline{0.042}$ & 0.067 & 0.02 & 0.01 & $\underline{0.004}$ & 0.005 \\
\hline 2OMEs/Total & 0.07 & 0.04 & $7.0 \times 10^{-7}$ & $1.8 \times 10^{-6}$ & 0.06 & 0.04 & $\underline{0.003}$ & 0.007 & 0.09 & 0.04 & $\underline{4.1 \times 10^{-4}}$ & $6.7 \times 10^{-4}$ \\
\hline 4OHEs/2OHEs & 0.13 & 0.12 & 0.503 & 0.595 & 0.11 & 0.12 & 0.142 & 0.184 & 0.17 & 0.12 & $\underline{0.013}$ & 0.016 \\
\hline TUMOR & $\begin{array}{c}\text { W } \\
n=17\end{array}$ & $\begin{array}{c}\text { M } \\
n=15\end{array}$ & $\begin{array}{c}P \\
\text { W vs. M }\end{array}$ & FDR & $\begin{array}{c}W \\
n=8\end{array}$ & $\underset{n=5}{M}$ & $\begin{array}{c}P \\
\text { W vs. M }\end{array}$ & FDR & $\begin{array}{c}\text { W } \\
n=9\end{array}$ & $\begin{array}{c}\text { M } \\
n=10\end{array}$ & $\begin{array}{c}P \\
\text { W vs. M }\end{array}$ & FDR \\
\hline $\mathrm{E}_{1}$ & 9.79 & 5.84 & $\underline{4.9 \times 10^{-7}}$ & $1.1 \times 10^{-6}$ & 8.77 & 5.20 & $\underline{0.002}$ & 0.003 & 12.02 & 6.79 & $\underline{2.2 \times 10^{-5}}$ & $7.0 \times 10^{-5}$ \\
\hline $\mathrm{E}_{2}$ & 20.86 & 9.18 & $\underline{1.4 \times 10^{-8}}$ & $6.3 \times 10^{-8}$ & 18.73 & 8.96 & $\underline{0.002}$ & 0.003 & 24.36 & 10.15 & $\underline{2.2 \times 10^{-5}}$ & $7.0 \times 10^{-5}$ \\
\hline $\mathrm{E}_{3}$ & 4.87 & 2.88 & $\underline{1.8 \times 10^{-6}}$ & $2.9 \times 10^{-6}$ & 4.22 & 2.26 & $\underline{0.011}$ & 0.016 & 5.18 & 2.90 & $1.5 \times 10^{-4}$ & $2.2 \times 10^{-4}$ \\
\hline $2 \mathrm{OHE}_{1}$ & 4.10 & 1.96 & $\underline{4.9 \times 10^{-7}}$ & $1.1 \times 10^{-6}$ & 3.43 & 1.92 & $\underline{0.002}$ & 0.003 & 4.76 & 2.09 & $\underline{4.3 \times 10^{-5}}$ & $8.0 \times 10^{-5}$ \\
\hline $2 \mathrm{OHE}_{2}$ & 1.82 & 0.76 & $\underline{7.1 \times 10^{-9}}$ & $4.6 \times 10^{-8}$ & 1.23 & 0.76 & $\underline{0.002}$ & 0.003 & 2.47 & 0.74 & $\underline{2.2 \times 10^{-5}}$ & $7.0 \times 10^{-5}$ \\
\hline $4 \mathrm{OHE}_{1}$ & 0.70 & 0.23 & $\underline{3.2 \times 10^{-6}}$ & $4.7 \times 10^{-6}$ & 0.69 & 0.23 & $\underline{0.011}$ & 0.016 & 0.70 & 0.24 & $\underline{8.7 \times 10^{-5}}$ & $1.4 \times 10^{-4}$ \\
\hline $4 \mathrm{OHE}_{2}$ & 0.31 & 0.12 & $\underline{9.5 \times 10^{-6}}$ & $1.2 \times 10^{-5}$ & 0.17 & 0.13 & 0.065 & 0.085 & 0.42 & 0.12 & $\underline{2.2 \times 10^{-5}}$ & $7.0 \times 10^{-5}$ \\
\hline $2 \mathrm{OME}_{1}$ & 1.73 & 0.62 & $7.1 \times 10^{-9}$ & $4.6 \times 10^{-8}$ & 1.73 & 0.49 & $\underline{0.002}$ & 0.003 & 1.73 & 0.63 & $\underline{4.3 \times 10^{-5}}$ & $8.0 \times 10^{-5}$ \\
\hline $2 \mathrm{OME}_{2}$ & 1.13 & 0.32 & $\underline{2.5 \times 10^{-8}}$ & $8.0 \times 10^{-8}$ & 1.37 & 0.27 & $\underline{0.002}$ & 0.003 & 1.13 & 0.34 & $\underline{4.3 \times 10^{-5}}$ & $8.0 \times 10^{-5}$ \\
\hline 2OHEs/Total & 0.12 & 0.12 & 0.411 & 0.411 & 0.12 & 0.12 & 0.222 & 0.262 & 0.11 & 0.11 & 1.000 & 1.000 \\
\hline 4OHEs/Total & 0.02 & 0.02 & 0.261 & 0.283 & 0.02 & 0.02 & 0.943 & 0.943 & 0.02 & 0.02 & 0.095 & 0.103 \\
\hline 2OMEs/Total & 0.06 & 0.04 & $\underline{1.8 \times 10^{-6}}$ & $2.9 \times 10^{-6}$ & 0.07 & 0.04 & $\underline{0.006}$ & 0.012 & 0.06 & 0.04 & $\underline{0.001}$ & 0.001 \\
\hline 4OHEs/2OHEs & 0.14 & 0.13 & 0.165 & 0.194 & 0.14 & 0.13 & 0.943 & 0.943 & 0.21 & 0.13 & $\underline{0.028}$ & 0.033 \\
\hline
\end{tabular}

*Values represent the medians. Estrogen and its metabolites in lung tissue from NSCLC patients were analyzed by LC-MS2. Statistical comparisons were based on the Wilcoxon rank sum test, with $P \leq 0.05$ considered significant (underlined). Bold highlight denotes where both the $P$ values and FDR are $\leq 0.05$. W: women; M: men.

genes (CYP17A, CYP19, HSD17B1, CYP21 and HSD3B1) was detected more frequently in tumor tissue than in normal tissue, with CYP19 (aromatase) and HSD3B1 only detected in tumors. Genes involved in estrogen metabolism (CYP1B1, GSTA4, GSTT1, NQO1 and COMT) were also expressed at a high frequency in lung tissue $(87-100 \%)$ (Figure 1), suggesting that human bronchoalveolar cells can both synthesize and metabolize estrogen.

\section{Estrogen and its metabolites are present in human lung tissue and altered during tumor formation}

To confirm the function of estrogen metabolizing enzymes within the lung, tissue (tumor and adjacent normal) from 35 non-small cell lung cancer (NSCLC) patients was analyzed for 16 estrogens/estrogen metabolites using a liquid chromatography/tandem mass spectrometry $\left(\mathrm{LC}-\mathrm{MS}^{2}\right)$ assay. Eighty percent of all subjects were non-Hispanic whites and $89 \%$ of the women were postmenopausal $(16 \geq$ age 55 plus one hysterectomy). $\mathrm{E}_{1}, \mathrm{E}_{2}, \mathrm{E}_{3}$ and 6 estrogen metabolites (2$\mathrm{OHE}_{1}, 2-\mathrm{OHE}_{2}, 4-\mathrm{OHE}_{1}, 4-\mathrm{OHE}_{2}, 2-\mathrm{OME}_{1}$, and 2- $\mathrm{OME}_{2}$ ) were detected within the human lung (Table 1), while 4-methoxyestrone (4-OME $)$, 4-methoxyestradiol (4$\left.\mathrm{OME}_{2}\right)$, 2-hydroxyestrone-3-methyl ether (3-OME $)$, $16 \alpha$-hydroxyestrone $\left(16 \alpha-\mathrm{OHE}_{1}\right), 16$-epiestriol (16-epiE $\left.\mathrm{e}_{3}\right)$, 17-epiestriol (17-epiE ${ }_{3}$ ), and 16-ketoestradiol (16-ketoE ${ }_{2}$ ) were not detected. $\mathrm{E}_{2}$ was the most abundant pulmonary estrogen species detected and $2-\mathrm{OHE}_{1}$ was the estrogen 
metabolite present at the highest concentration in the human lung (Table 1). Concentrations of 4-OHEs were lower than those of 2-OHEs and 2-OMEs. Interestingly, although the concentration of $\mathrm{E}_{2}$ in human lung tissue was higher than that of $\mathrm{E}_{1}$, levels of 2-OHE, $2-\mathrm{OME}_{2}$ and $4-\mathrm{OHE}_{2}$ were lower than those of $2-\mathrm{OHE}_{1}, 2-\mathrm{OME}_{1}$ and 4-OHE $\mathrm{OH}_{1}$.

To assess if estrogen synthesis and metabolism are altered during lung tumorigenesis, the levels of estrogen and its metabolites in lung tumors were compared to those of matched normal tissue (paired samples were available for 32 of the 35 NSCLC patients). The level of each estrogen and estrogen metabolite was higher in the tumor as compared to matched normal tissue $(P<0.05$, Figure 2A), irrespective of the patient's sex and smoking status. Most importantly, the percentage of 4-OHEs remained significantly elevated in lung tumors vs. matched normal tissue from both men and women $(P<0.05)$, while

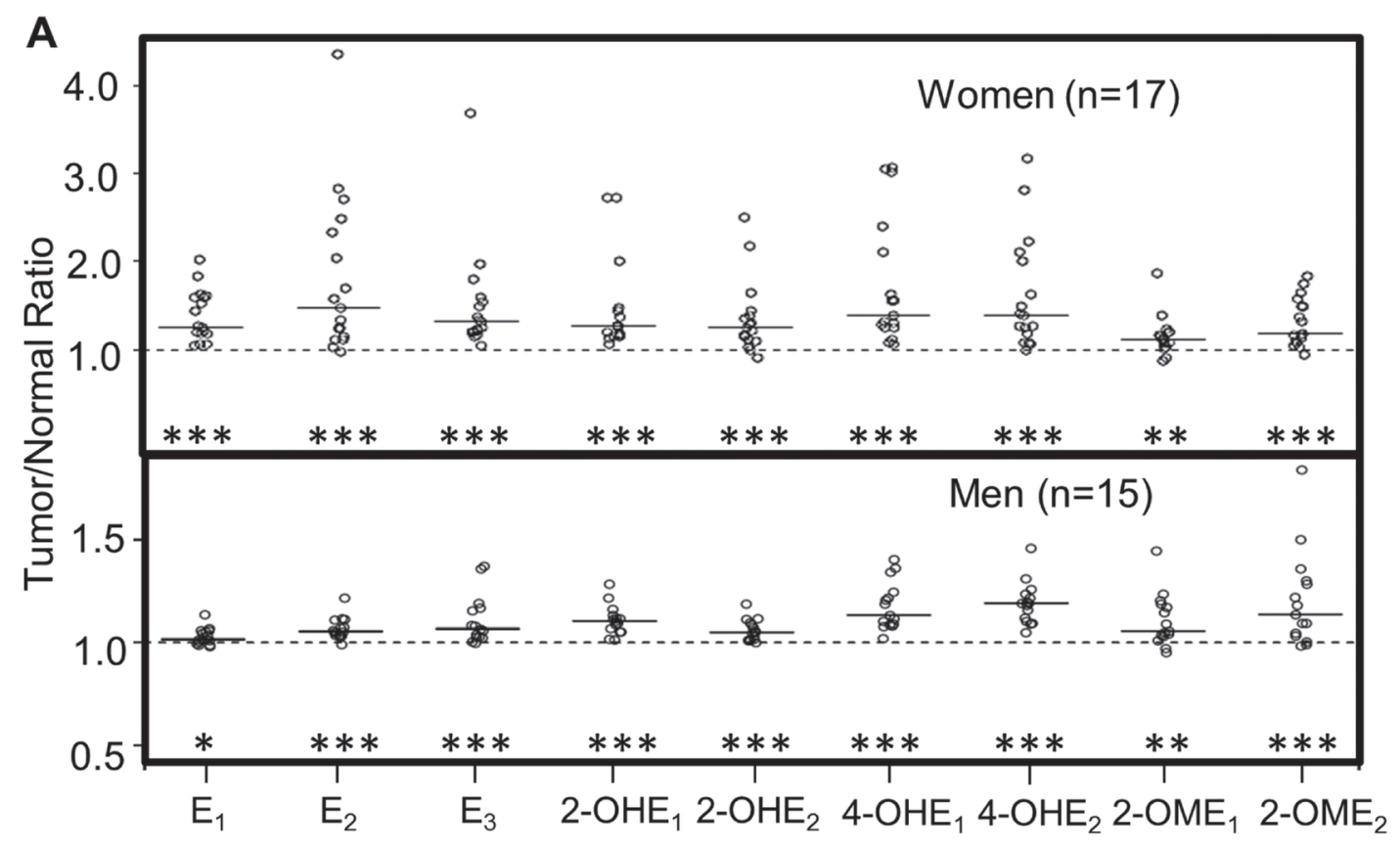

B
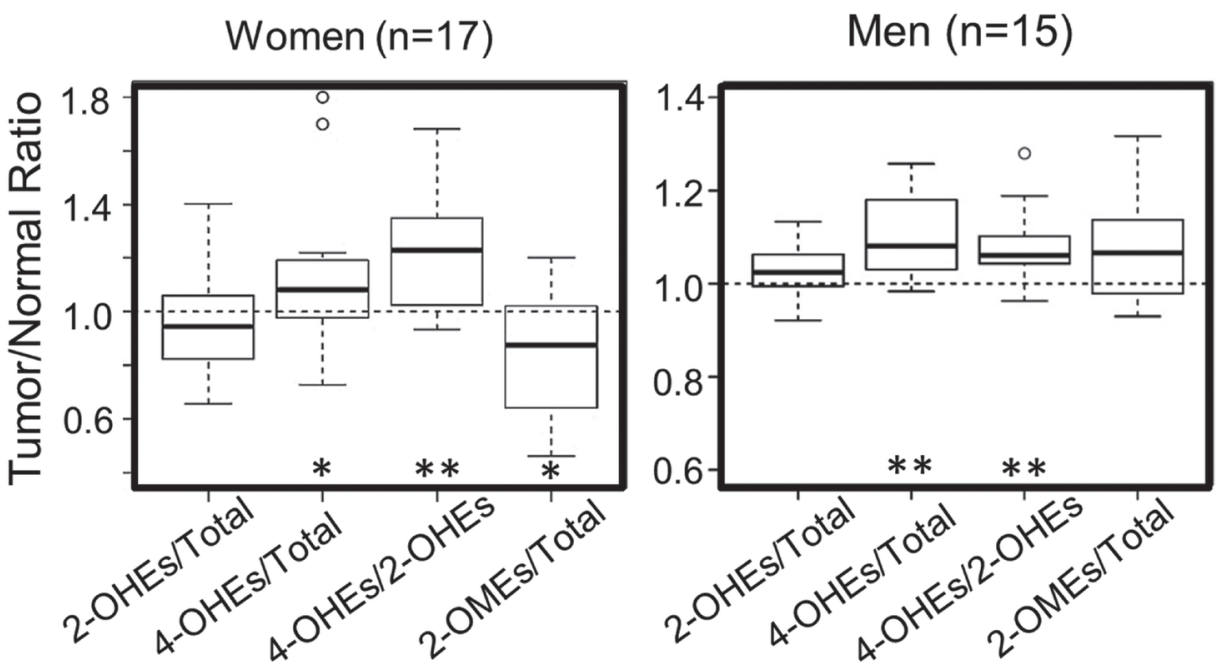

Figure 2: Comparison of estrogen and estrogen metabolites in lung tumors vs. adjacent normal lung tissue from NSCLC patients. (A) Fold difference (tumor/normal ratio) in estrogen and estrogen metabolites in tumor vs. paired normal lung tissue. The median of the independent values (open circles) is shown as a solid horizontal line. (B) The level of 2-OHEs, 4-OHEs and 2-OMEs (\% total estrogens and estrogen metabolites) and the ratio of 4-OHEs/2-OHEs in lung tumors vs. paired normal lung tissue were calculated. The fold difference between tumor and paired normal lung tissue (tumor/normal ratio) is plotted. The box plots denote the median and the 75th and 25th percentiles (inter-quartile range, IQR). The "whiskers" represent the most extreme points ( $\leq 1.5$ times the IQR). Outliers are plotted outside the box. Values above 1 indicate the levels of estrogen or estrogen metabolites are higher in lung tumors. Comparisons between normal and tumor tissue were performed using the Wilcoxon signed rank test. The FDR was calculated to adjust for multiple comparisons $\left({ }^{*} P<0.05 ;{ }^{* *} P<0.01 ;{ }^{* * *} P<0.001\right)$. 
Table 2: Levels of estrogen and its metabolites in never- vs. current-smoking women*

\begin{tabular}{|c|c|c|c|c|c|c|c|c|c|c|c|c|}
\hline & \multicolumn{4}{|c|}{ Normal (pg/g tissue) } & \multicolumn{4}{|c|}{ Tumor (pg/g tissue) } & \multicolumn{4}{|c|}{ Urine (pg/mg creatinine) } \\
\hline & $\begin{array}{c}\mathrm{N} \\
\boldsymbol{n}=\mathbf{9}\end{array}$ & $\begin{array}{c}\text { C } \\
n=9\end{array}$ & $\begin{array}{c}P \\
\text { N vs. C }\end{array}$ & FDR & $\begin{array}{c}\mathrm{N} \\
\boldsymbol{n}=\mathbf{8}\end{array}$ & $\begin{array}{c}\text { C } \\
n=9\end{array}$ & $\begin{array}{c}P \\
\text { N vs. C }\end{array}$ & FDR & $\begin{array}{c}\mathrm{N} \\
\boldsymbol{n}=\mathbf{3}\end{array}$ & $\begin{array}{c}C \\
n=4\end{array}$ & $\begin{array}{c}P \\
\text { N vs. C }\end{array}$ & FDR \\
\hline $\mathrm{E}_{1}$ & 6.85 & 10.32 & 0.340 & 0.402 & 8.77 & 12.02 & 0.074 & 0.242 & 24.97 & 32.70 & 0.857 & 1.000 \\
\hline $\mathrm{E}_{2}$ & 13.11 & 18.19 & 0.190 & 0.275 & 18.73 & 24.36 & 0.200 & 0.371 & 8.24 & 12.75 & 0.857 & 1.000 \\
\hline $\mathrm{E}_{3}$ & 3.02 & 4.93 & 0.077 & 0.167 & 4.22 & 5.18 & 0.200 & 0.371 & 20.85 & 28.02 & 1.000 & 1.000 \\
\hline $2 \mathrm{OHE}_{1}$ & 2.32 & 2.97 & 0.094 & 0.174 & 3.43 & 4.76 & 0.139 & 0.361 & 32.42 & 60.74 & 1.000 & 1.000 \\
\hline $2 \mathrm{OHE}_{2}$ & 1.04 & 2.16 & $\underline{0.004}$ & 0.017 & 1.23 & 2.47 & $\underline{0.021}$ & 0.234 & 13.56 & 43.25 & 0.628 & 1.000 \\
\hline $4 \mathrm{OHE}_{1}$ & 0.30 & 0.45 & $\underline{0.050}$ & 0.131 & 0.69 & 0.70 & 0.321 & 0.418 & 5.57 & 22.11 & 0.114 & 0.743 \\
\hline $4 \mathrm{OHE}_{2}$ & 0.12 & 0.35 & $\underline{0.001}$ & 0.008 & 0.17 & 0.42 & $\underline{0.036}$ & 0.234 & 1.94 & 11.58 & 0.057 & 0.495 \\
\hline $2 \mathrm{OME}_{1}$ & 1.38 & 1.55 & 0.297 & 0.386 & 1.73 & 1.73 & 0.815 & 0.883 & 7.64 & 11.05 & 0.400 & 1.000 \\
\hline $2 \mathrm{OME}_{2}$ & 0.85 & 0.92 & 0.387 & 0.419 & 1.37 & 1.13 & 0.673 & 0.795 & 1.89 & 2.59 & 0.400 & 1.000 \\
\hline 2OHEs/Total & 0.10 & 0.12 & 0.162 & 0.262 & 0.12 & 0.11 & 1.000 & 1.000 & 0.40 & 0.37 & 0.400 & 1.000 \\
\hline 4OHEs/Total & 0.01 & 0.02 & $\underline{0.006}$ & 0.018 & 0.02 & 0.02 & 0.277 & 0.400 & 0.06 & 0.18 & 0.057 & 0.371 \\
\hline 2OMEs/Total & 0.06 & 0.09 & 1.000 & 1.000 & 0.07 & 0.06 & 0.236 & 0.383 & 0.08 & 0.07 & 1.000 & 1.000 \\
\hline 4OHEs/2OHEs & 0.11 & 0.17 & $\underline{0.001}$ & 0.008 & 0.14 & 0.21 & 0.059 & 0.242 & 0.15 & 0.52 & 0.057 & 0.371 \\
\hline
\end{tabular}

"Values represent the medians. Statistical comparisons were based on the Wilcoxon rank sum test, with $P \leq 0.05$ considered significant (underlines above as indicated). Bold highlight denotes FDR values $\leq 0.05$. N: never smokers; C: current smokers.

the percentage of 2-OHEs did not differ significantly between lung tumors and normal tissue in women $(P=0.21)$ or men $(P=0.12)$ (Figure $2 \mathrm{~B})$. As a result, the ratio of 4-OHEs/2-OHEs was significantly higher in lung tumors as compared to paired normal tissue $(P<0.001$, Figure $2 \mathrm{~B}$ ). Interestingly, the proportion of protective 2-OMEs was lower in lung tumors than in normal tissue from women $(P=0.014)$, but a trend of higher levels in tumor vs. normal tissue was observed in men $(P=0.08)$ (Figure 2B).

\section{Sex differences in the level of estrogen and estrogen metabolites in human lung tissue}

As expected, the levels of most estrogens and estrogen metabolites, including $\mathrm{E}_{2}, 2-\mathrm{OHE}_{1}, 2-\mathrm{OHE}_{2}, 4-\mathrm{OHE}_{1}$, $2-\mathrm{OME}_{1}$, and $2-\mathrm{OME}_{2}$, were significantly higher in normal lung tissue from women vs. men who never smoked. Likewise, the levels of all estrogen metabolites, except for $4-\mathrm{OHE}_{2}$, were higher in tumors from never-smoking women as compared to never-smoking men. Among current-smokers, the levels of all 9 estrogens and estrogen metabolites detected were elevated significantly in both normal lung tissue and tumors from women vs. men (Table 1). Interestingly, the percentage of 4-OHEs $\left(\left(4-\mathrm{OHE}_{1}+4-\mathrm{OHE}_{2}\right) /\right.$ total $)$ within the normal lung was lower in women vs. men who neversmoked, while the opposite was observed among currentsmokers (Figure 3A). In contrast, no significant sex difference in the percentage of 2-OHEs was observed in human lung tissue (normal or tumor), irrespective of smoking status. The percentage of 2-OMEs was $\sim 2$-fold higher in both normal lung tissue and tumors from women as compared to men, independent of smoking history.

\section{Impact of tobacco smoke on estrogen metabolism within the human lung}

To elucidate the effect of tobacco smoke on estrogen metabolism, the concentration of estrogens and estrogen metabolites in lung tissue (normal or tumor) from NSCLC patients who never smoked was compared with that of current-smokers. Among women, smoking significantly increased the level of $2-\mathrm{OHE}_{2}, 4-\mathrm{OHE}_{1}$ and $4-\mathrm{OHE}_{2}$ within the normal lung, and 2- $\mathrm{OHE}_{2}$ and $4-\mathrm{OHE}_{2}$ in lung tumors, but did not alter the level of 2-OMEs $\left(2-\mathrm{OME}_{1}\right.$ or 2-OME ${ }_{2}$ ) in either normal or tumor tissue (Table 2). Furthermore, both the percentage of 4-OHEs and the ratio of 4-OHEs/2-OHEs were increased significantly in normal lung tissue from current- vs. never-smoking women (Table 2, Figure 3B), but not in corresponding tumor tissue (Figure 3B). After adjusting for multiple comparisons, the difference in 2-- $\mathrm{OHE}_{2}, 4-\mathrm{OHE}_{2}, 4-\mathrm{OHEs} /$ total and 4-OHEs/2-OHEs between current- and neversmoking women was still significant with a false discovery rate $($ FDR $)<0.05$. Interestingly, smoking did not cause any significant change in the level of pulmonary estrogen metabolites in men with NSCLC (Table 3). For those women with NSCLC where matched samples of urine and lung tissue were available, the percentage of urinary 4-OHEs was higher in current- vs. never-smokers (Figure 3B). However, the increase did not achieve statistical significance, most likely due to the limited sample size. 
Table 3: Levels of estrogen and its metabolites in the lung of never- vs. current-smoking men*

\begin{tabular}{|c|c|c|c|c|c|c|}
\hline & \multicolumn{3}{|c|}{ Normal (pg/g tissue) } & \multicolumn{3}{|c|}{ Tumor (pg/g tissue) } \\
\hline & $\begin{array}{c}\mathrm{N} \\
\boldsymbol{n}=7\end{array}$ & $\begin{array}{c}\text { C } \\
n=10\end{array}$ & $\begin{array}{c}P \\
\text { N vs. C }\end{array}$ & $\begin{array}{c}\mathrm{N} \\
n=5\end{array}$ & $\begin{array}{c}\mathrm{C} \\
n=10\end{array}$ & $\begin{array}{c}P \\
\text { N vs. C }\end{array}$ \\
\hline $\mathrm{E}_{1}$ & 5.47 & 6.46 & 0.23 & 5.20 & 6.79 & 0.08 \\
\hline $\mathrm{E}_{2}$ & 8.73 & 9.42 & 0.19 & 8.96 & 10.15 & 0.17 \\
\hline $\mathrm{E}_{3}$ & 2.14 & 2.67 & 0.81 & 2.26 & 2.90 & 0.59 \\
\hline $2 \mathrm{OHE}_{1}$ & 1.69 & 1.98 & 0.42 & 1.92 & 2.09 & 0.68 \\
\hline $2 \mathrm{OHE}_{2}$ & 0.72 & 0.68 & 0.81 & 0.76 & 0.74 & 0.86 \\
\hline $4 \mathrm{OHE}_{1}$ & 0.20 & 0.21 & 0.54 & 0.23 & 0.24 & 0.77 \\
\hline $4 \mathrm{OHE}_{2}$ & 0.10 & 0.10 & 0.81 & 0.13 & 0.12 & 0.95 \\
\hline $2 \mathrm{OME}_{1}$ & 0.51 & 0.52 & 0.89 & 0.49 & 0.63 & 0.77 \\
\hline $2 \mathrm{OME}_{2}$ & 0.25 & 0.30 & 0.60 & 0.27 & 0.34 & 0.25 \\
\hline 2OHEs/Total & 0.12 & 0.12 & 0.19 & 0.12 & 0.11 & 0.25 \\
\hline 4OHEs/Total & 0.01 & 0.01 & 0.11 & 0.02 & 0.02 & 0.13 \\
\hline 2OMEs/Total & 0.04 & 0.04 & 0.74 & 0.04 & 0.04 & 0.77 \\
\hline 4OHEs/2OHEs & 0.12 & 0.12 & 0.89 & 0.14 & 0.13 & 0.95 \\
\hline
\end{tabular}

"Values represent the medians. Statistical comparisons were based on the Wilcoxon rank sum test. N: never smokers; C: current smokers.
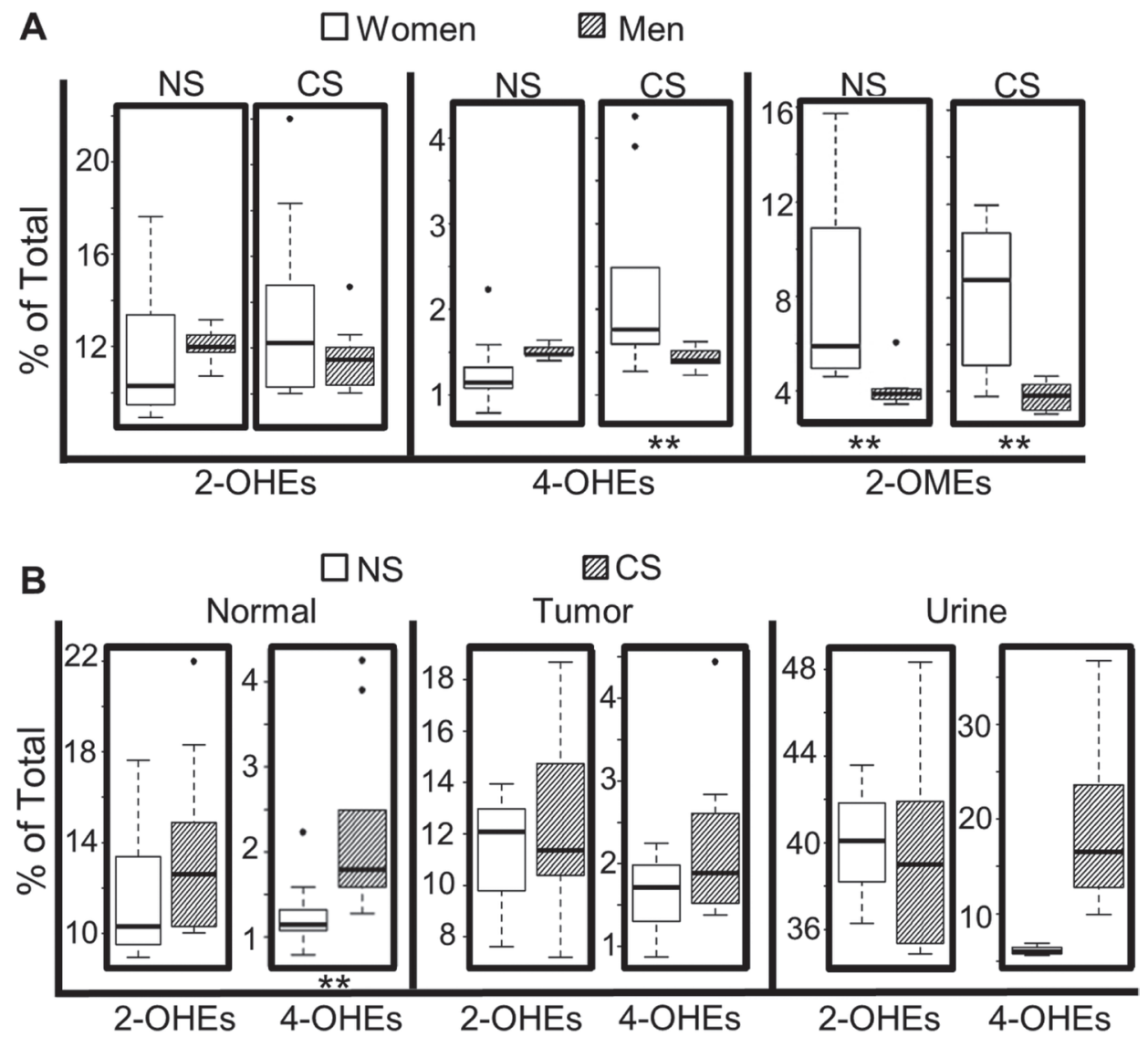

Figure 3: Impact of sex and smoking status on levels of estrogen metabolites. (A) Comparison of estrogen metabolites in normal lung tissue from women vs. men. (B) Comparison of 4-OHEs and 2-OHEs in normal lung tissue, lung tumors and urine from women with NSCLC who are never-smokers (NS) or current-smokers (CS). Box plots denote the median and the 75th and 25th percentiles (interquartile range, IQR). The "whiskers" represent the most extreme points $(\leq 1.5$ times the IQR). Outliers are outside the box. $P$ values are based on the Wilcoxon rank sum test $\left({ }^{* *} P<0.01\right)$. 


\section{Differences in the urinary estrogen metabolites of Caucasian and Chinese American women}

Potential racial differences in estrogen metabolism were explored by comparing the levels of urinary estrogens and estrogen metabolites from postmenopausal Caucasian and Chinese American women who never smoked. All Chinese American women donors were healthy and residing in Philadelphia. The majority (89\%) were immigrants, with a mean time in the US of 19 years. Levels of urinary estrogens and estrogen metabolites from Chinese American women ( $N=20$, age 55-65) were compared with archival data for 19 healthy Caucasian women matched for age and body mass index (19.2-24.8). As shown in Figure 4, Chinese American women had $80 \%$ more 4-OHEs ( $\%$ total) $(P=0.015)$ and 2 -fold less 2 -OHEs (\% total) $(P=$ $0.0002)$ in their urine as compared to Caucasian women. The percentage of 2-OMEs did not differ significantly with race/ethnicity. The ratio of urinary 4-OHEs/2-OHEs was also $80 \%$ higher $(P=0.0001)$ in Chinese women.

\section{DISCUSSION}

The present study is the first to demonstrate that estrogen metabolites are present in human lung tissue. This finding extends previous reports from others indicating that $E_{1}$ and $E_{2}$ and transcripts/proteins encoded by estrogen synthesis genes [31-33] are present in human lung tissue. Gene expression profiling of bronchoalveolar cells revealed that the lung could both synthesize and metabolize estrogens. Detection of unconjugated 2-OHEs, 4-OHEs, 2-OMEs, but not 16-OHEs $\left(16 \alpha-\mathrm{OHE}_{1}, 16-\mathrm{epiE}_{3}, 17-\mathrm{epiE}_{3}, 16-\mathrm{ketoE}_{2}\right)$ suggests that pulmonary estrogens are metabolized primarily via 2- and 4-hydroxylation. Of note, 16-hydroxy estrogens were not detected in the murine lung after hydrolysis, thus it is unlikely that $16 \alpha-\mathrm{OHE}_{1}$ is involved in lung carcinogenesis. Because the human lung tissue was not perfused, one cannot conclude definitively that the human lung metabolizes estrogen. However, while unconjugated 2-OHE and 4-OHE were detected in human lung tissue in the present study, 2-OHE or 4-OHE have not been detected previously in serum in unconjugated forms $[16,27]$. This difference suggests that some estrogen metabolites are produced locally in the lung.

Consistent with enhanced estrogen synthesis in lung tumors [31,34], our results demonstrate that estrogen/ estrogen metabolite levels are elevated in lung tumors as compared to paired normal tissue (Figure 2). However, the observed elevation of 4-OHEs ( $\%$ total) and 4-OHEs/2OHEs in lung tumors suggests a shift in metabolism towards 4-hydroxylation during tumor formation. Given that 4-OHEs are estrogenic and genotoxic, an increase could promote tumor development. Interestingly, the percentage of protective estrogen metabolites (2-OMEs) is reduced in lung tumors from women, but increased, although not significantly, in tumors from men. This suggests a sex difference in the O-methylation of catechol estrogens during lung tumor formation. Future longitudinal and/or case-control studies are required to fully understand the relationship between estrogen metabolism and lung cancer and determine if high levels of oncogenic estrogen metabolites and/or low levels of protective estrogen metabolites accelerate lung carcinogenesis.

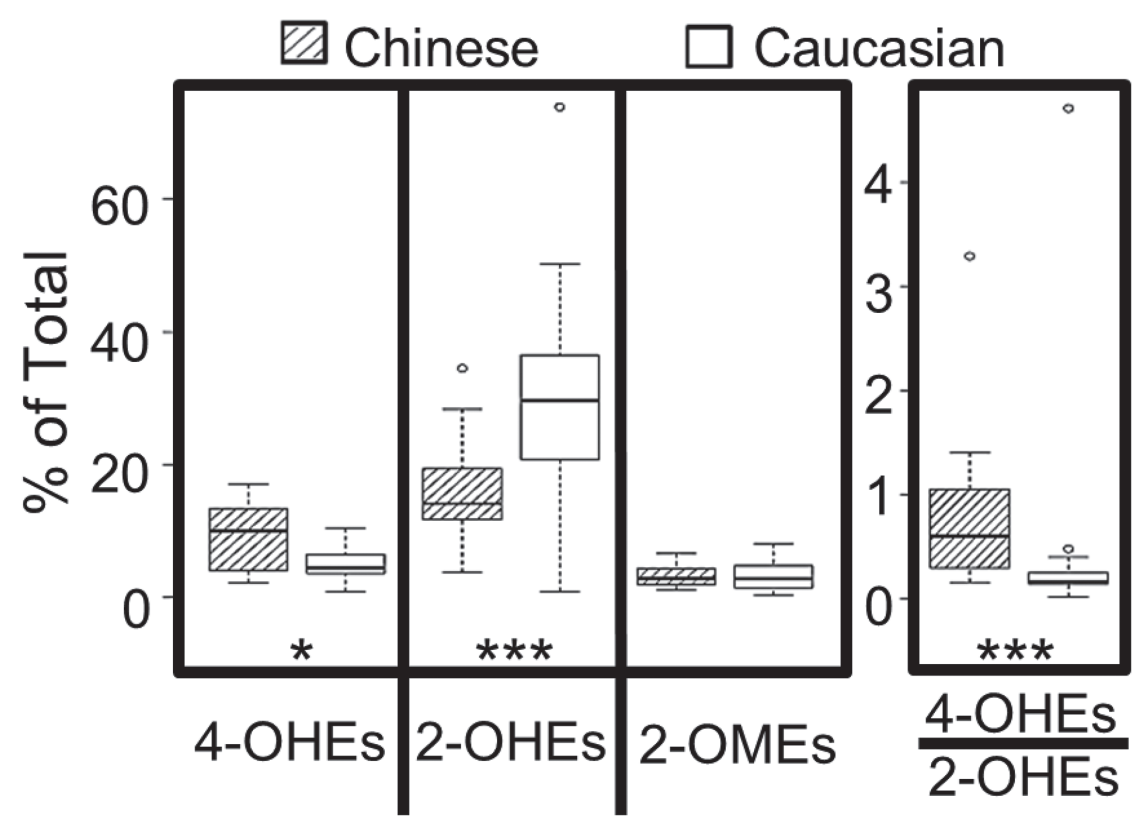

Figure 4: Level of urinary catechol estrogens (\% total estrogens and estrogen metabolites) in healthy postmenopausal Chinese $(n=20)$ vs. Caucasian $(n=19)$ American women who never smoked. The box plots denote the median and the 25 th and 75 th percentiles (inter-quartile range, IQR). The "whiskers" represent the most extreme points $(\leq 1.5$ times the IQR). Outliers are outside the boxes. $P$ values are based on the Wilcoxon rank sum test $\left({ }^{*} P<0.05 ;{ }^{* * *} P<0.001\right)$. 
Data from the present study provide strong evidence that estrogen metabolism varies with sex, smoking status and race/ethnicity, all risk factors for lung cancer. Higher levels of both pulmonary estrogens and estrogen metabolites in women vs. men could lead to enhanced activation of ER signaling in women and accelerate tumor progression. The level of $\mathrm{E}_{2}$ within the lungs (normal and tumor tissue) of Japanese postmenopausal women with NSCLC is lower than that of men [34], a discrepancy that may be attributed to differences in smoking status (not reported) or race/ethnicity. In the present study, the sex difference in the percentage of 4-OHEs depended on smoking status: 4-OHEs were more abundant in normal lung tissue of never-smoking men vs. women. The opposite was observed among currentsmokers (Figure 3A). Because smoking shifts estrogen metabolism towards 4-hydroxylation in women but not in men (Figure 3B), the percentage of 4-OHEs in the normal lung tissue of women may be elevated to the same level as in men after smoke exposure. Sex differences were also observed in the levels of protective 2-OMEs (both as absolute concentration and \% total), which were higher in the lungs (normal and tumor tissue) of women as compared to men, irrespective of smoking status.

This is the first report that tobacco smoke alters pulmonary estrogen metabolites in humans. Tobacco smoke did not induce a significant change in the level of any of the estrogen metabolites within the lungs of men (normal or tumor, Table 3), but significantly changed estrogen metabolism within the lungs of women. Tobacco smoke exposure led to increased levels of $2-\mathrm{OHE}_{2}$ $(P=0.004)$ in normal lung tissue, although it did not alter the percentage of 2-OHEs or the levels of 2-OMEs (Table 2). However, 4-hydroxylation (4-OHE 1 and 4-OHE 2 levels, the percentage of 4-OHEs and the ratio of 4-OHEs/2OHEs) in normal lung tissue was increased significantly among current-smokers as compared to never-smokers. Therefore, tobacco smoke induces a shift in estrogen metabolism towards a harmful pathway, which could contribute to lung carcinogenesis specifically in women. On the other hand, neither the percentage of 4-OHEs nor the 4-OHEs/2-OHEs ratio was different in lung tumors from current- and never-smokers, suggesting that other factors increase 4-hydroxylation of estrogens in never-smokers during carcinogenesis. Furthermore, tobacco smoke exposure elevated $4-\mathrm{OHEs}(\%$ total $)$ in both lung tissue and matched urine samples (the urinary results did not achieve significance, possibly due to the small sample size). This finding is consistent with that of a recent study showing that tobacco smoke increased 2- and 4-hydroxylation and decreased $\mathrm{O}$-methylation of estrogens in the urine of healthy pre-menopausal women [20]. It also suggests that the smoking-induced increase in 4-hydroxylation of estrogen in the lung is present in urine samples. Additional studies are needed to confirm the potential use of urine as a surrogate for estrogen metabolite levels in lung tissue.
Data from this study indicate that never-smoking postmenopausal Chinese women have a more active 4-hydroxylation pathway (and less 2-hydroxylation activity) than Caucasians. Interestingly, the levels of 2-OMEs (\% total) did not differ between the two groups (Figure 4). Racial/ethnic differences in estrogen metabolism could result from race/ethnic group-specific polymorphisms in estrogen metabolizing genes [21] as well as environmental exposures due to varying life styles (i.e. soy (phytoestrogen) intake [35], exposure to cooking oil fumes and/or secondhand smoke). A larger case controlled study is needed to assess the contribution of excess 4-OHEs to the high risk of lung cancer faced by never-smoking Chinese women. Given the genotoxicity of 4-OHEs and the high frequency of acquired EGFR mutations in Asian women with lung cancer [36], it will be important to determine if 4-OHEs accelerate the rate of EGFR mutation.

Striking similarity exists between the metabolism of estrogen in the lungs of mice [18] and humans. First, $\mathrm{E}_{1}$, $\mathrm{E}_{2}, \mathrm{E}_{3}, 2$-OHEs, 4-OHEs and 2-OMEs, but not 16-hydroxy estrogens, were detected in both species, with $\mathrm{E}_{2}$ being the most abundant. However, although 4-OHEs were the most abundant estrogen metabolites in the murine lung, their level was less than that of 2-OHEs and 2-OMEs in the human lung. Second, the level of most estrogens and estrogen metabolites was higher in females (mice and humans). Third, exposure to tobacco smoke increased the production of 4-OHEs. The impact of over production of this putative carcinogen on lung cancer risk is of great interest.

In summary, the discovery of estrogen metabolism within the human lung provides exciting opportunities to further investigate the role of estrogen metabolites in lung tumorigenesis. The present data demonstrate a higher proportion of 4-OHEs and a shift from 2-hydroxylation to 4-hydroxylation (higher 4-OHEs/2-OHEs ratio) in lung tumors (vs. paired normal tissue) and in urine samples from populations at higher risk for lung cancer, including currentsmokers (vs. never-smokers) and never-smoking Chinese American women (vs. Caucasian women). Future studies will assess the utility of 4-OHEs (in tissue and/or urine) as biomarkers of lung cancer risk. Therapeutic interventions that either inhibit the production of 4-OHEs and/or promote the generation of 2-OMEs could confer protection from genotoxicity. Establishment of a link between the causal effects of 4-OHEs and lung cancer will provide strong rationale for targeting the enzyme(s) responsible for their synthesis, a novel strategy for the prevention of this disease.

\section{MATERIALS AND METHODS}

\section{Subjects and specimens}

NSCLC patients undergoing surgery (19982014) at Fox Chase Cancer Center (FCCC), were enrolled irrespective of sex, age, race/ethnicity, stage, 


\begin{tabular}{|c|c|}
\hline $\begin{array}{l}\text { Race/Ethnicity } \\
\text { Caucasian }\end{array}$ & $39(80 \%)$ \\
\hline $\begin{array}{l}\text { African American } \\
\text { Asian }\end{array}$ & $\begin{array}{l}7(14 \%) \\
3(6 \%)\end{array}$ \\
\hline $\begin{array}{l}\text { Gender } \\
\text { Male }\end{array}$ & $22(45 \%)$ \\
\hline Female & $27(55 \%)$ \\
\hline $\begin{array}{l}\text { Age Range: } 38-81 \\
\geq 55 \\
<55\end{array}$ & $\begin{array}{c}43(88 \%) \\
6(12 \%)\end{array}$ \\
\hline $\begin{array}{l}\text { Smoking Status* } \\
\text { Never-Smokers }\end{array}$ & $18(37 \%)$ \\
\hline Ever-Smokers & $31(63 \%)$ \\
\hline $\begin{array}{l}\text { Current } \\
\text { Former } \\
\text { Quitting Time Unknown }\end{array}$ & $\begin{array}{c}19(39 \%) \\
8(16 \%) \\
4(8 \%)\end{array}$ \\
\hline $\begin{array}{l}\text { Menopause status ( } 27 \text { women) } \\
\text { Post-menopausal }{ }^{* *} \\
\text { Unknown }\end{array}$ & $\begin{array}{c}25(93 \%) \\
2(7 \%)\end{array}$ \\
\hline $\begin{array}{l}\text { Histopathology } \\
\text { Adenocarcinoma } \\
\text { Squamous Cell Carcinoma } \\
\text { Mixed Adeno and Squamous }\end{array}$ & $\begin{array}{c}44(90 \%) \\
4(8 \%) \\
1(2 \%)\end{array}$ \\
\hline $\begin{array}{l}\text { Lung Tissue Sample } \\
\text { Tumor } \\
\text { Normal } \\
\text { Paired }\end{array}$ & $\begin{array}{l}44(90 \%) \\
43(88 \%) \\
32(65 \%)\end{array}$ \\
\hline Urine Sample & $15(31 \%)$ \\
\hline
\end{tabular}

* Never smokers - defined as individuals who had smoked fewer than 100 cigarettes in their lifetime. Individuals with a smoking history were categorized as former or current smokers based on when they quit smoking ( $\geq$ or $<6$ months prior to surgery, respectively).

** Includes 24 women $\geq 55$ years of age and one woman ( 47 years old) who underwent hysterectomy (ovaries intact).

prior chemotherapy or radiation, smoking history or menopausal status. Lung tissue (paired normal-appearing and tumor) and/or urine samples were collected at the time of surgery for gene expression analyses and/or measurement of estrogens and estrogen metabolites. Never-smokers were defined as people who used $<100$ cigarettes in their lifetime. Individuals were categorized as former- or current-smokers based on quitting smoking $\geq$ or $<6$ months prior to surgery, respectively. Table 4 summarizes the characteristics of all NSCLC patients. Detailed information for each subject is provided in Supplementary Table 1 .

Self-identified healthy Chinese American women were recruited from the Philadelphia area. A one-time urine sample was collected from eligible, postmenopausal never-smokers and shipped to the University of Minnesota for estrogen analyses. The urinary estrogen metabolite profiles of Asian women were compared to archived samples from Caucasian American women matched for smoking status and of a similar age and body mass index. All studies were approved by the Institutional Review Boards at FCCC, Temple University and the University of Minnesota.

\section{Gene expression analyses}

Surgically resected lung tissue was snap-frozen in optimal cutting temperature medium. Bronchoalveolar cells $(\sim 1500$, normal and tumor) were laser microdissected from H\&E stained sections ( $5 \mu \mathrm{m}$ ) using the PixCell $\AA$ IITM system (Arcturus Bioscience, Inc.). RNA was isolated and qRT-PCR performed [26] using gene-specific primers (Table 5). 


\begin{tabular}{|c|c|}
\hline Genes & Primer Catalogue Numbers \\
\hline TFRC & Hs99999911_m1 \\
\hline$T B P$ & Hs99999910_m1 \\
\hline $18 S$ & Hs99999903_m1 \\
\hline ESR1 & Hs00174860_m1 \\
\hline ESR2 & Hs00230957_m1 \\
\hline CYP11B1 & Hs01596404_m1 \\
\hline CYP17A1 & Hs00164375_m1 \\
\hline CYP21 & Hs00416901_g1 \\
\hline CYP19 & Hs00903406_ml \\
\hline$H S D 3 B 1$ & Hs00426435_m1 \\
\hline$H S D 17 B 1$ & Hs00166219_g1 \\
\hline$H S D 17 B 3$ & Hs00609319_m1 \\
\hline$H S D 17 B 7$ & Hs00996127_m1 \\
\hline CYP1B1 & Hs00164383_m1 \\
\hline CYP1A1 & Hs00153120_m1 \\
\hline GSTM1 & Hs02341469_m1 \\
\hline GSTA4 & Hs00155308_m1 \\
\hline GSTT1 & Hs00184475_m1 \\
\hline NQO1 & Hs00168547_m1 \\
\hline COMT & Hs00241349_ml \\
\hline
\end{tabular}

\section{Measurement of estrogens and estrogen metabolites in lung tissue}

Profiling of estrogen and estrogen metabolites in lung tissue was performed at Leidos Biomedical Research, Inc., Frederick, MD, using a LC-MS ${ }^{2}$ assay described previously by this group [18], except that samples were not hydrolyzed to remove $\beta$-glucuronide and sulfate conjugates from estrogen metabolites. The limit of detection was approximately $20 \mathrm{fg}$ estrogen metabolite on column. The same protocol, when used to extract estrogen metabolites from another highly complex protein mixture (serum), yielded an extraction efficiency of $90-105 \%$.

\section{Measurement of estrogens and estrogen metabolites in urine}

Estrogens and estrogen metabolites were extracted from urine samples of NSCLC patients and analyzed at Leidos Biomedical Research, Inc., Frederick (without hydrolysis). Urine samples from healthy Caucasian and Chinese American women were processed and analyzed at the University of Minnesota, as described previously [28]. Estrogens and estrogen metabolites (12 species, excluding 16-epiE $3,17-\mathrm{epiE}_{3}, 16-\mathrm{ketoE}_{2}$, and 3-OME ${ }_{1}$ ) were measured using a Thermo Electron Quantum Discovery Max Triple Quadrupole LC-MS ${ }^{2}$ instrument, with $\beta$-glucuronide and sulfate conjugates hydrolyzed
[28, 29]. Quantitative analysis was conducted using Thermo Electron Xcalibur proprietary software. Each sample was measured in duplicate and the coefficient of variation was less than $15 \%$. Urinary creatinine concentrations were determined using the Creatinine Colorimetric Assay Kit (Cayman Chemical).

\section{Statistical analyses}

The two-sided Wilcoxon rank sum test or signed rank test was used to compare estrogen or estrogen metabolites levels between two groups (as described in the results). Multiple comparisons were adjusted by calculating the Benjamini-Hochberg FDR [30].

\section{Author contributions}

Conception and design: Jing Peng, Sibele I. Meireles, Mindy S. Kurzer, Grace X. Ma and Margie L. Clapper. Collection and assembly of data: Jing Peng, Sibele I. Meireles, Xia Xu, William E. Smith, Stacy L. Riel, Shumenghui Zhai, Guo Zhang, Xiang Ma. Data analysis and interpretation: Jing Peng, Sibele I. Meireles, Michael J. Slifker, Mindy S. Kurzer, Margie L. Clapper. Figure preparation and article writing/editing: Jing Peng, Sibele I. Meireles, Michael J. Slifker, Grace X. Ma, Margie L. Clapper. All authors provided final approval of the manuscript. 


\section{ACKNOWLEDGMENTS}

The authors wish to thank Drs. Carolyn M. Dresler, Melvin Goldberg, Stacey Su, Walter J. Scott and Prashant C. Shah for collecting specimens; Dr. Jessica R. Bauman for verifying patient information; Drs. Jose Russo, Hossein Borghaei, and Edna Cukierman for their invaluable comments; Darlene Curran for her excellent assistance in preparing this article for publication; and all patients who participated in this study. The following core facilities at Fox Chase Cancer Center contributed to this study: Biosample Repository Facility, Laser Microdissection Component of the Experimental Histopathology Facility, and the RealTime PCR Component of the Genomics Facility.

\section{CONFLICTS OF INTEREST}

The authors have no conflicts of interest to disclose.

\section{FUNDING}

This work was supported by the National Cancer Institute at the National Institute of Health (P30 CA006927); an appropriation from the Commonwealth of Pennsylvania; the Keystone Program at the Fox Chase Cancer Center; the Estate of Jane Villon; the Kitty Jackson Fund and generous donations from Arnold, Jerome and Spencer Zaslow, Aurora M. and Timothy P. Hughes, and Barbara R. and Alfonse J. Gabriele.

\section{REFERENCES}

1. Parkin DM, Bray F, Ferlay J, Pisani P. Global cancer statistics, 2002. CA Cancer J Clin. 2005; 55:74-108. https:// doi.org $/ 55 / 2 / 74$

2. Sun S, Schiller JH, Gazdar AF. Lung cancer in never smokers--a different disease. Nat Rev Cancer. 2007; 7:77890. https://doi.org/10.1038/nrc2190.

3. Epplein M, Schwartz SM, Potter JD, Weiss NS. Smokingadjusted lung cancer incidence among Asian-Americans (United States). Cancer Causes Control. 2005; 16:1085-90. https://doi.org/10.1007/s10552-005-0330-6.

4. Siegfried JM, Stabile LP. Estrongenic steroid hormones in lung cancer. Semin Oncol. 2014; 41:5-16. https://doi. org/10.1053/j.seminoncol.2013.12.009.

5. Tsuchiya Y, Nakajima M, Yokoi T. Cytochrome P450mediated metabolism of estrogens and its regulation in human. Cancer Lett. 2005; 227:115-24. https://doi. org/10.1016/j.canlet.2004.10.007.

6. Badawi AF, Cavalieri EL, Rogan EG. Role of human cytochrome P450 1A1, 1A2, 1B1, and 3A4 in the 2-, 4-, and 16alpha-hydroxylation of 17beta-estradiol. Metabolism. 2001; 50:1001-3. https://doi.org/10.1053/meta.2001.25592.

7. Cavalieri EL, Rogan EG. Unbalanced metabolism of endogenous estrogens in the etiology and prevention of human cancer. J Steroid Biochem Mol Biol. 2011; 125:16980. https://doi.org/10.1016/j.jsbmb.2011.03.008.

8. Fishman J, Osborne MP, Telang NT. The role of estrogen in mammary carcinogenesis. Ann N Y Acad Sci. 1995; 768:91-100.

9. Cavalieri EL, Rogan EG. A unifying mechanism in the initiation of cancer and other diseases by catechol quinones. Ann N Y Acad Sci. 2004; 1028:247-57. https://doi. org/10.1196/annals.1322.029.

10. Zahid M, Kohli E, Saeed M, Rogan E, Cavalieri E. The greater reactivity of estradiol-3,4-quinone vs estradiol-2,3quinone with DNA in the formation of depurinating adducts: implications for tumor-initiating activity. Chem Res Toxicol. 2006; 19:164-72. https://doi.org/10.1021/tx050229y.

11. Sepkovic DW, Bradlow HL. Estrogen hydroxylation--the good and the bad. Ann N Y Acad Sci. 2009; 1155:57-67. https://doi.org/10.1111/j.1749-6632.2008.03675.x.

12. Zhu BT, Conney AH. Functional role of estrogen metabolism in target cells: review and perspectives. Carcinogenesis. 1998; 19:1-27.

13. Fotsis T, Zhang Y, Pepper MS, Adlercreutz H, Montesano R, Nawroth PP, Schweigerer L. The endogenous oestrogen metabolite 2-methoxyoestradiol inhibits angiogenesis and suppresses tumour growth. Nature. 1994; 368:237-9. https://doi.org/10.1038/368237a0.

14. Verenich S, Gerk PM. Therapeutic promises of 2-methoxyestradiol and its drug disposition challenges. Mol Pharm. 2010; 7:2030-9. https://doi.org/10.1021/mp100190f.

15. Rogan EG, Badawi AF, Devanesan PD, Meza JL, Edney JA, West WW, Higginbotham SM, Cavalieri EL. Relative imbalances in estrogen metabolism and conjugation in breast tissue of women with carcinoma: potential biomarkers of susceptibility to cancer. Carcinogenesis. 2003; 24:697-702.

16. Fuhrman BJ, Schairer C, Gail MH, Boyd-Morin J, Xu X, Sue LY, Buys SS, Isaacs C, Keefer LK, Veenstra TD, Berg CD, Hoover RN, Ziegler RG. Estrogen metabolism and risk of breast cancer in postmenopausal women. J Natl Cancer Inst. 2012; 104:326-39. https://doi.org/10.1093/jnci/djr531.

17. Shatalova EG, Klein-Szanto AJ, Devarajan K, Cukierman E, Clapper ML. Estrogen and cytochrome P450 1B1 contribute to both early- and late-stage head and neck carcinogenesis. Cancer Prev Res (Phila). 2011; 4:107-15. https://doi.org/10.1158/1940-6207.CAPR-10-0133.

18. Peng J, Xu X, Mace BE, Vanderveer LA, Workman LR, Slifker MJ, Sullivan PM, Veenstra TD, Clapper ML. Estrogen metabolism within the lung and its modulation by tobacco smoke. Carcinogenesis. 2013; 34:909-15. https:// doi.org/10.1093/carcin/bgs402.

19. Meireles SI, Esteves GH, Hirata R Jr, Peri S, Devarajan K, Slifker M, Mosier SL, Peng J, Vadhanam MV, Hurst HE, Neves EJ, Reis LF, Gairola CG, et al. Early changes in gene expression induced by tobacco smoke: Evidence for the importance of estrogen within lung tissue. Cancer Prev Res (Phila Pa). 2010; 3:707-17. https://doi.org/10.1158/19406207.CAPR-09-0162. 
20. Gu F, Caporaso NE, Schairer C, Fortner RT, Xu X, Hankinson $\mathrm{SE}$, Eliassen AH, Ziegler RG. Urinary concentrations of estrogens and estrogen metabolites and smoking in caucasian women. Cancer Epidemiol Biomarkers Prev. 2013; 22:58-68. https://doi.org/10.1158/1055-9965.EPI-12-0909.

21. Sowers MR, Wilson AL, Kardia SR, Chu J, McConnell DS. CYP1A1 and CYP1B1 polymorphisms and their association with estradiol and estrogen metabolites in women who are premenopausal and perimenopausal. Am J Med. 2006; 119:S44-51. https://doi.org/10.1016/j.amjmed.2006.07.006.

22. Tang YM, Green BL, Chen GF, Thompson PA, Lang NP, Shinde A, Lin DX, Tan W, Lyn-Cook BD, Hammons GJ, Kadlubar FF. Human CYP1B1 Leu432Val gene polymorphism: ethnic distribution in African-Americans, Caucasians and Chinese; oestradiol hydroxylase activity; and distribution in prostate cancer cases and controls. Pharmacogenetics. 2000; 10:761-6.

23. Palmatier MA, Kang AM, Kidd KK. Global variation in the frequencies of functionally different catechol-Omethyltransferase alleles. Biol Psychiatry. 1999; 46:557-67.

24. Pinheiro SP, Holmes MD, Pollak MN, Barbieri RL, Hankinson SE. Racial differences in premenopausal endogenous hormones. Cancer Epidemiol Biomarkers Prev. 2005; 14:2147-53. https://doi.org/10.1158/1055-9965.EPI-04-0944.

25. Setiawan VW, Haiman CA, Stanczyk FZ, Le Marchand L, Henderson BE. Racial/ethnic differences in postmenopausal endogenous hormones: the multiethnic cohort study. Cancer Epidemiol Biomarkers Prev. 2006; 15:1849-55. https://doi. org/10.1158/1055-9965.EPI-06-0307.

26. Salaun M, Peng J, Hensley HH, Roder N, Flieder DB, Houlle-Crepin S, Abramovici-Roels O, Sabourin JC, Thiberville L, Clapper ML. MMP-13 In-Vivo Molecular Imaging Reveals Early Expression in Lung Adenocarcinoma. PLoS One. 2015; 10:e0132960. https:// doi.org/10.1371/journal.pone.0132960.

27. Xu X, Roman JM, Issaq HJ, Keefer LK, Veenstra TD, Ziegler RG. Quantitative measurement of endogenous estrogens and estrogen metabolites in human serum by liquid chromatography-tandem mass spectrometry. Anal Chem. 2007; 79:7813-21. https://doi.org/10.1021/ ac070494j.

28. Xu X, Keefer LK, Ziegler RG, Veenstra TD. A liquid chromatography-mass spectrometry method for the quantitative analysis of urinary endogenous estrogen metabolites. Nat Protoc. 2007; 2:1350-5. https://doi. org/10.1038/nprot.2007.176.
29. Smith AJ, Phipps WR, Thomas W, Schmitz KH, Kurzer MS. The effects of aerobic exercise on estrogen metabolism in healthy premenopausal women. Cancer Epidemiol Biomarkers Prev. 2013; 22:756-64. https://doi. org/10.1158/1055-9965.EPI-12-1325.

30. Benjamini Y, Hochberg Y. Controlling the False Discovery Rate: A Practical and Powerful Approach to Multiple Testing. Journal of the Royal Statistical Society Series B (Methodological). 1995; 57:289-300.

31. Marquez-Garban DC, Chen HW, Goodglick L, Fishbein $\mathrm{MC}$, Pietras RJ. Targeting aromatase and estrogen signaling in human non-small cell lung cancer. Ann N Y Acad Sci. 2009; 1155:194-205. https://doi.org/10.1111/j.17496632.2009.04116.x.

32. Miki Y, Suzuki T, Abe K, Suzuki S, Niikawa H, Iida S, Hata S, Akahira J, Mori K, Evans DB, Kondo T, Yamada-Okabe $\mathrm{H}$, Sasano $\mathrm{H}$. Intratumoral localization of aromatase and interaction between stromal and parenchymal cells in the non-small cell lung carcinoma microenvironment. Cancer Res. 2010; 70:6659-69. https://doi.org/10.1158/0008-5472. CAN-09-4653.

33. Weinberg OK, Marquez-Garban DC, Fishbein MC, Goodglick L, Garban HJ, Dubinett SM, Pietras RJ. Aromatase Inhibitors in Human Lung Cancer Therapy. Cancer Res. 2005; 65:11287-91. https://doi. org/10.1158/0008-5472.can-05-2737.

34. Niikawa H, Suzuki T, Miki Y, Suzuki S, Nagasaki S, Akahira J, Honma S, Evans DB, Hayashi S, Kondo T, Sasano H. Intratumoral estrogens and estrogen receptors in human non-small cell lung carcinoma. Clin Cancer Res. 2008; 14:4417-26. https://doi.org/10.1158/1078-0432.CCR07-1950.

35. Fuhrman BJ, Pfeiffer R, Xu X, Wu AH, Korde L, Gail MH, Keefer LK, Veenstra TD, Hoover RN, Ziegler RG. Soy intake is associated with increased 2-hydroxylation and decreased 16alpha-hydroxylation of estrogens in AsianAmerican women. Cancer Epidemiol Biomarkers Prev. 2009; 18:2751-60. https://doi.org/10.1158/1055-9965.EPI09-0388.

36. Ha SY, Choi SJ, Cho JH, Choi HJ, Lee J, Jung K, Irwin D, Liu X, Lira ME, Mao M, Kim HK, Choi YS, Shim YM, et al. Lung cancer in never-smoker Asian females is driven by oncogenic mutations, most often involving EGFR. Oncotarget. 2015; 6:5465-74. https://doi.org/10.18632/ oncotarget. 2925 . 